\title{
Associations between socioeconomic status and blood cadmium levels in Korea
}

\author{
Yongho Jee, Sung-il Cho \\ Department of Public Health Science, Graduate School of Public Health, Seoul National University, Seoul, Korea
}

OBJECTIVES: Although smoking is associated with both low socioeconomic status and blood cadmium (Cd) levels, the association between socioeconomic status and $\mathrm{Cd}$ levels remains unclear. Therefore, our study aimed to examine this association and to clarify whether smoking is a confounding or mediating variable in this relationship.

METHODS: Data $(n=7,734)$ were drawn from the Korea National Health and Nutrition Examination Survey (KNHANES, 20082011), including years that contained data on blood $\mathrm{Cd}$ and urinary cotinine levels. We investigated the associations of income, education, and occupation with blood Cd levels. Smoking was investigated by categorizing participants by smoking status (never, former, and current) and pack-years into quartiles. The weekly frequency of rice and barley intake was analyzed to gain insights into participants' dietary patterns. Additionally, urinary cotinine levels were used to ensure the validity of the smoking variables.

RESULTS: Participants earning a low income and with less formal education had higher blood Cd levels. After controlling for smoking, the association between income and Cd levels substantially weakened. Further controlling for education, the association between income and $\mathrm{Cd}$ levels disappeared. However, there was a strong negative association between education and $\mathrm{Cd}$ levels, even after controlling for smoking history, pack-years, and urinary cotinine levels.

CONCLUSIONS: In cross-sectional data from the KNHANES, blood Cd levels were significantly higher among those with a low income and less formal education. Smoking history contributed to, but did not fully explain, these associations.

KEY WORDS: Cadmium, Smoking, Socioeconomic status, Korea National Health and Nutrition Examination Survey

\section{INTRODUCTION}

Cadmium (Cd) is well known as a heavy metal used in our daily life, occupational and environmental exposure to which is harmful to the human body. Cd is toxic even at low exposure levels, and has acute and chronic effects on health and the environment [1]. Since Cd is not biodegradable, it remains in circulation once re-

\section{Correspondence: Sung-il Cho}

Department of Public Health Science, Graduate School of Public Health, Seoul National University, 1 Gwanak-ro, Gwanak-gu, Seoul 08826, Korea

E-mail: scho@snu.ac.kr

Received: Jan 9, 2019 / Accepted: May 15, 2019 / Published: May 15, 2019

This article is available from: http://e-epih.org/

(C) This is an open-access article distributed under the terms of the Creative Commons Attribution License (http://creativecommons.org/licenses/by/4.0/) which permits unrestricted use, distribution, and reproduction in any medium, provided the original work is properly cited.

(C) 2019, Korean Society of Epidemiology leased into the environment [2-4]. The routes through which humans are exposed to Cd are commonly categorized as occupational exposure and environmental exposure (non-occupational exposure). The occupational route involves exposure to $\mathrm{Cd}$ by the mining, production, and consumption of non-ferrous metal or plating, welding, the utilization of storage batteries and agricultural chemicals, and pesticide production [5]. Environmental exposure to $\mathrm{Cd}$ most often occurs through food intake such as meat, shellfish, vegetables, and any form of food whose packaging contains Cd; moreover, exposure to cigarette smoking and dust from polluted soil are routes of chronic exposure [6,7]. In Korea, smoking prevalence was extremely high in the 2000s. According to a report by Jee et al. [7], the prevalence of smoking among males in Korea in 2000 was $68 \%$. Furthermore, rice consumption is considered to be a major factor associated with high Cd levels in Asian countries, including Korea [8].

The environmental route usually involves lower levels of exposure, and therefore a lower risk of resulting disease, than occupational exposure. However, some health effects have been reported 
to be associated with low-level exposure, such as blood pressure elevation and kidney function degradation. Furthermore, since environmental exposure to $\mathrm{Cd}$ involves numerous aspects of daily activities, is globally recognized as a public health hazard, and may disproportionately affect vulnerable groups such as children, pregnant females, and the elderly, the potential effects of $\mathrm{Cd}$ exposure should be a concern from a public health perspective.

However, few studies have examined the associations of socioeconomic variables such as income level, education level, and occupation with Cd levels, together with an analysis of the possible confounding effect of smoking.

\section{MATERIALS AND METHODS}

\section{Subjects}

The data used in this study were drawn from the fourth and fifth waves of the Korea National Health and Nutrition Examination Survey (KNHANES IV and V, 2007-2012) conducted by the Korean Centers for Disease Control and Prevention (KCDC) and the Ministry of Health and Welfare, a nationally representative sample recruited using a multi-stage clustered probability design. The data included respondents from 20 years to 87 years of age. Children and adolescents were excluded since only adults received testing for heavy metal levels. The data were obtained from 2 independent cross-sectional waves of the KNHANES (2007-2009, 2010-2012), and were limited to years that contained data on blood Cd and urinary cotinine levels $(2008,2009,2010,2011)$. The sample size of the participants with data blood Cd and urinary cotinine levels was 7,734 .

\section{Study variables}

Education level, income, and occupation were included as socioeconomic factors in this study, following previous studies by Tyrrell et al. [9] and McKelvey et al. [10]. Participants were classified by age into 5 groups (20-29, 30-39, 40-49, 50-59, and $\geq 60$ years). Education level was classified into 4 groups by each participant's final level of schooling (less than elementary school graduate, middle school graduate, high school graduate, and college graduate). Occupation was originally categorized into 7 groups (managers, clerical workers, service workers, agricultural, fishery workers, craft workers, elementary workers, and unemployed) based on the Korean Standard Classification of Occupations of the Korea National Statistical Office. However, for the present study, occupations were reclassified into 4 categories (professional and managers; non-manual, skilled, and semi-skilled workers; unskilled workers; and unemployed), following the classification used in the Whitehall study [11].

\section{Blood cadmium levels}

The average blood Cd level was $1.24 \mu \mathrm{g} / \mathrm{L}$ (standard deviation [SD], 1.24; range, 0.02-8.34) for male and $1.57 \mu \mathrm{g} / \mathrm{L}$ (SD, 0.62; range, 0.02-6.03) for female. Cd levels were not normally distributed; instead, the data were left-skewed. Therefore, log-transformed val- ues or geometric mean values were used for the analysis in this study.

\section{Statistical analysis}

A complex sampling design was used for the KNHANES data, including stratification, clusters, and weights to represent the entire Korean population. The demographic characteristics and the prevalence are presented as weighted percentages to describe nationally representative data, as calculated using PROC SURVEYMEANS and PROC SURVEYREG. Initially, descriptive statistics were computed for all study variables, including frequencies and percentages for categorical variables, and means and SDs for continuous variables.

Next, we investigated the association of Cd levels with income by comparing the $\mathrm{Cd}$ levels between the highest income quartile (Q4) and the lowest income quartile (Q1). The association between Cd levels and education was investigated by comparing blood Cd levels between college graduates and those who had completed an elementary-school education or less. Occupational associations were investigated by using the occupation classification variable of the KNHANES to compare Cd levels between professionals and managers and the unemployed. Associations

Table 1. General characteristics of the study subjects stratified by year, KNHANES

\begin{tabular}{lllll}
\hline Characteristics & \multicolumn{1}{c}{2008} & \multicolumn{1}{c}{2009} & \multicolumn{1}{c}{2010} & \multicolumn{1}{c}{2011} \\
\hline Total participants (n) & 9,744 & 10,533 & 8,958 & 8,518 \\
Study participants (n) & 1,936 & 1,964 & 1,916 & 1,918 \\
Sex, male (\%) & 49.9 & 50.0 & 49.3 & 49.5 \\
Age, mean \pm SD (yr) & $45.5 \pm 15.5$ & $45.5 \pm 15.5$ & $45.3 \pm 14.5$ & $45.1 \pm 14.5$ \\
Education & & & & \\
Less than primary & $455(22.7)$ & $419(21.2)$ & $359(18.5)$ & $310(15.9)$ \\
Middle school & $242(12.1)$ & $225(11.4)$ & $203(10.5)$ & $209(10.7)$ \\
High school & $751(37.5)$ & $748(37.8)$ & $694(35.8)$ & $736(37.7)$ \\
College or more & $533(27.6)$ & $587(29.7)$ & $683(35.2)$ & $700(35.8)$ \\
Occupation & & & & \\
Managers & $229(11.5)$ & $261(13.2)$ & $283(14.5)$ & $292(14.9)$ \\
Clerical workers & $142(7.1)$ & $182(9.2)$ & $211(10.9)$ & $181(9.3)$ \\
Service workers & $250(12.6)$ & $272(13.8)$ & $274(14.2)$ & $265(13.6)$ \\
Agricultural, fishery & $156(7.8)$ & $114(5.8)$ & $155(8.0)$ & $114(5.8)$ \\
Craft workers & $213(10.7)$ & $229(11.6)$ & $217(11.3)$ & $243(12.4)$ \\
Elementary & $199(10.0)$ & $179(9.1)$ & $137(7.1)$ & $157(8.0)$ \\
Unemployed & $801(40.3)$ & $738(37.4)$ & $651(33.8)$ & $702(35.9)$ \\
Income (quantile) & & & & \\
Bottom (Q1) & $497(25.5)$ & $512(25.9)$ & $506(26.1)$ & $466(23.7)$ \\
Second (Q2) & $478(24.5)$ & $497(25.2)$ & $494(25.5)$ & $509(23.7)$ \\
Middle (Q3) & $491(25.2)$ & $483(24.5)$ & $469(21.2)$ & $491(25.0)$ \\
Fourth (Q4) & $485(24.9)$ & $483(24.5)$ & $470(24.2)$ & $502(25.5)$ \\
\hline
\end{tabular}

Values are presented as number (\%).

KNHANES, Korea National Health and Nutrition Examination Survey (a nationally representative sample recruited using a multi-stage clustered probability design); SD, standard deviation. 
between Cd levels and smoking were investigated by categorizing current smoking status, smoking amount, smoking duration, and pack-years into quartile variables. Additionally, urinary cotinine levels were used to ensure the validity of the smoking variables. SAS version 9.4 (SAS Institute Inc., Cary, NC, USA) was used for preliminary analyses, and Mplus version 7.4 (https://mplus.software.informer.com/7.4/) was used for the path analyses [12].

\section{Ethics statement}

Data from the KNHANES survey are made publicly available through the KNHANES website (http://knhanes.cdc.go.kr). Thus, ethical approval was not required for this study. All participants provided written informed consent.

\section{RESULTS}

\section{General characteristics of the study participants}

The general characteristics of the KNHANES study partici- pants are shown in Table 1. The differences in the age and sex distribution by year were negligible. However, the distribution of college graduates increased from $27.6 \%$ in 2008 to $35.8 \%$ in 2011 .

The distribution of the general characteristics of participants stratified by sex is presented in Table 2 . The sample size of female $(n=3,913,51.0 \%)$ was slightly larger than that of male $(n=3,821$, $49.0 \%)$. The average body mass index was higher in male than in female. The average cotinine level and number of current smokers among male was approximately 7 times higher than among female. The proportion of participants with an elementary education or less was higher in female (25.5\%) than in male (13.5\%). Furthermore, approximately twice as many of the unemployed participants were female (50.2\%) than male (22.5\%).

\section{Association between income and blood cadmium levels}

Table 3 demonstrates trends in the association between income and blood Cd levels by sequentially controlling for other varia-

Table 2. Characteristics of study participants with data on blood Cd levels and cotinine levels, KNHANES ( $n=7,734)$

\begin{tabular}{|c|c|c|c|c|}
\hline Variables & Total & Weighted & $\begin{array}{c}\text { Blood Cd }(\mu \mathrm{g} / \mathrm{L})^{1} \\
\text { GM }(95 \% \mathrm{Cl})\end{array}$ & $\mathrm{p}$-value \\
\hline \multicolumn{5}{|l|}{ Age (yr) } \\
\hline $20-29$ & $1,493(19.3)$ & $3,497,948(27.8)$ & 1.00 (reference) & \\
\hline $30-39$ & $1,568(20.3)$ & $2,646,615(21.0)$ & $0.87(0.84,0.91)$ & $<0.001$ \\
\hline $40-49$ & $1,571(20.3)$ & $2,778,299(22.1)$ & $1.08(1.05,1.11)$ & $<0.001$ \\
\hline $50-59$ & $1,549(20.0)$ & $2,235,992(17.7)$ & $1.22(1.18,1.25)$ & $<0.001$ \\
\hline$\geq 60$ & $1,553(20.1)$ & $1,438,462(11.4)$ & $1.24(1.20,1.27)$ & $<0.001$ \\
\hline \multicolumn{5}{|l|}{ Sex } \\
\hline Male & $3,821(49.4)$ & $7,121,327(56.5)$ & 1.00 (reference) & \\
\hline Female & $3,913(50.6)$ & $5,475,988(43.5)$ & $1.01(0.98,1.03)$ & $<0.001$ \\
\hline \multicolumn{5}{|l|}{ Education } \\
\hline Elementary or less & $1,512(19.5)$ & $1,735,973(13.8)$ & 1.00 (reference) & \\
\hline Middle school & $860(11.1)$ & $1,247,189(9.9)$ & $1.18(1.14,1.24)$ & $<0.001$ \\
\hline High school & $2,877(37.2)$ & $5,258,149(41.7)$ & $0.88(0.85,0.90)$ & $<0.001$ \\
\hline University or more & $2,485(32.1)$ & $4,356,004(34.6)$ & $0.77(0.75,0.79)$ & $<0.001$ \\
\hline \multicolumn{5}{|l|}{ Household income } \\
\hline Q4 (high) & $1,950(25.2)$ & $3,271,804(26.0)$ & 1.00 (reference) & \\
\hline Q3 & $1,955(25.3)$ & $3,182,180(25.3)$ & $0.89(0.86,0.92)$ & 0.095 \\
\hline Q2 & $1,905(24.6)$ & $3,102,698(24.6)$ & $0.94(0.91,0.97)$ & $<0.001$ \\
\hline Q1 (low) & $1,924(24.9)$ & $3,040,633(24.1)$ & $0.97(0.94,1.01)$ & $<0.001$ \\
\hline \multicolumn{5}{|l|}{ Occupation $(n=7,707)$} \\
\hline Professionals and managers & $1,055(13.7)$ & $1,915,934(15.3)$ & 1.00 (reference) & \\
\hline Non-manual, skilled workers & $3,179(41.2)$ & $5,408,467(43.1)$ & $0.94(0.92,0.98)$ & $<0.001$ \\
\hline Unskilled workers & $660(8.6)$ & $1,037,897(8.3)$ & $1.09(1.04,1.15)$ & $<0.001$ \\
\hline Unemployed & $2,813(36.5)$ & $4,176,645(33.3)$ & $0.90(0.87,0.93)$ & $<0.001$ \\
\hline \multicolumn{5}{|l|}{ Smoking status } \\
\hline Never & $4,166(53.9)$ & $6,137,777(48.7)$ & 1.00 (reference) & \\
\hline Former & $1,596(20.6)$ & $2,603,822(20.7)$ & $0.77(0.74,0.80)$ & $<0.001$ \\
\hline Current & $1,972(25.5)$ & $3,855,715(30.6)$ & $1.12(1.09,1.16)$ & $<0.001$ \\
\hline
\end{tabular}

Values are presented as number (\%).

Cd, cadmium; KNHANES, Korea National Health and Nutrition Examination Survey; GM, geometric mean; Cl, confidence interval.

${ }^{1}$ Age-adjusted GM with Cl. 
Table 3. Associations between income level and log-transformed blood cadmium levels $(n=7,707)^{1}$

\begin{tabular}{|c|c|c|c|c|c|c|}
\hline Variables & & Model 1 & Model 2 & Model 3 & Model 4 & Model 5 \\
\hline \multirow[t]{4}{*}{ Income level } & Q4 (high) & Reference & Reference & Reference & Reference & Reference \\
\hline & Q3 & $0.037(0.112)$ & $0.032(0.163)$ & $0.014(0.511)$ & $0.001(0.969)$ & $0.001(0.946)$ \\
\hline & Q2 & $0.081(<0.001)$ & $0.078(<0.001)$ & $0.046(0.033)$ & $0.022(0.317)$ & $0.022(0.309)$ \\
\hline & Q1 (low) & $0.108(<0.001)$ & $0.102(<0.001)$ & $0.046(0.042)$ & $0.007(0.776)$ & $0.009(0.682)$ \\
\hline \multirow[t]{2}{*}{ Sex } & Male & & Reference & Reference & Reference & Reference \\
\hline & Female & & $0.146(<0.001)$ & $0.384(<0.001)$ & $0.371(<0.001)$ & $0.376(<0.001)$ \\
\hline \multirow[t]{3}{*}{ Smoking status } & Never smoker & & & Reference & Reference & Reference \\
\hline & Ex-smoker & & & $0.056(0.018)$ & $0.057(0.015)$ & $0.057(0.016)$ \\
\hline & Current smoker & & & $0.546(<0.001)$ & $0.535(<0.001)$ & $0.533(<0.001)$ \\
\hline \multirow[t]{4}{*}{ Education } & University graduate or more & 4 & & & Reference & Reference \\
\hline & High school graduate & 3 & & & $0.087(<0.001)$ & $0.085(<0.001)$ \\
\hline & Middle school graduate & 2 & & & $0.144(<0.001)$ & $0.140(<0.001)$ \\
\hline & Elementary graduate or less & 1 & & & $0.180(<0.001)$ & $0.176(<0.001)$ \\
\hline \multirow[t]{4}{*}{ Occupation } & Professionals and managers & 1 & & & & Reference \\
\hline & Non-manual, skilled workers & 2 & & & & $0.020(0.380)$ \\
\hline & Unskilled workers & 3 & & & & $-0.008(0.801)$ \\
\hline & Unemployed & 4 & & & & $-0.009(0.685)$ \\
\hline $\mathrm{R}^{2}$ & & 0.205 & 0.219 & 0.336 & 0.343 & 0.344 \\
\hline
\end{tabular}

Values are presented as $\beta$ ( $p$-value).

'Adjusted for age (20-29, 30-39, 40-49, 50-59, and $\geq 60$ years), income level, sex, smoking status, education, and occupation.

bles, including sex, smoking status, education level, and occupation. A basic model comparing blood Cd levels by income level without sex stratification is shown in model 1 . The log-transformed blood Cd level in the lowest income group (Q1) was 0.108 $\mu \mathrm{g} / \mathrm{L}$ higher than in the highest income group, which was the reference group (model 1). When sex was further controlled, the association remained stable. However, after additionally controlling for smoking status, the association was somewhat attenuated, but remained significant. A sharp fluctuation occurred after controlling for education level, at which point the association between income and blood Cd levels was totally eliminated. Therefore, the association between income and blood Cd levels was confounded by smoking status and education level.

\section{Path analysis of the associations of age, income, education, and smoking pack-years with blood cadmium levels}

Figure 1A presents the results of a path analysis of the overall association of blood Cd levels with smoking pack-years and social determinants including income level, education level, and occupation classification in male. Smoking pack-years, income level, education level, and age all demonstrated significant associations with blood Cd levels. The association between income and smoking pack-years was -0.028 , which supported our hypothesis. The direct relevance of education level for blood Cd levels was -0.036 , while its indirect relevance to blood $\mathrm{Cd}$ levels by going through smoking pack-years was $-0.009(=-0.076 \times 0.115)$.

Figure $1 \mathrm{~B}$ presents the results of a path analysis of the overall association of blood Cd levels with smoking pack-years and social determinants including income level, education level, and occupation classification in female. Unlike the results for male, smoking pack-years, education level, and age were significantly associated with blood Cd levels. However, income did not show a significant association.

\section{DISCUSSION}

In this analysis of cross-sectional data from the KNHANES, we aimed to explain the association between blood Cd levels and income using a modeling method in which factors related to $\mathrm{Cd}$ levels, such as sex, smoking status, education, and occupation, were added step by step. Blood Cd levels were significantly higher among those with low income and less formal education. However, these associations were substantially attenuated after controlling for smoking status, although they still remained present. The results of this study suggest that blood Cd levels may also be a biomarker reflecting socioeconomic disparities. Moreover, interventions targeting Cd levels in individuals in the low-income and low-education groups who are highly exposed to $\mathrm{Cd}$ are needed. The results of our analysis correspond with existing results regarding health inequities and heavy metal exposure $[9,10]$. In this study, an association between income and blood Cd levels was found, but the magnitude of this association decreased from 0.126 to 0.050 in male and from 0.076 to 0.057 in female after controlling for smoking status. The sharp decrease in the magnitude of the association among male after controlling for smoking status seems to reflect the close association between smoking status and blood Cd levels. Therefore, the association between income and blood 

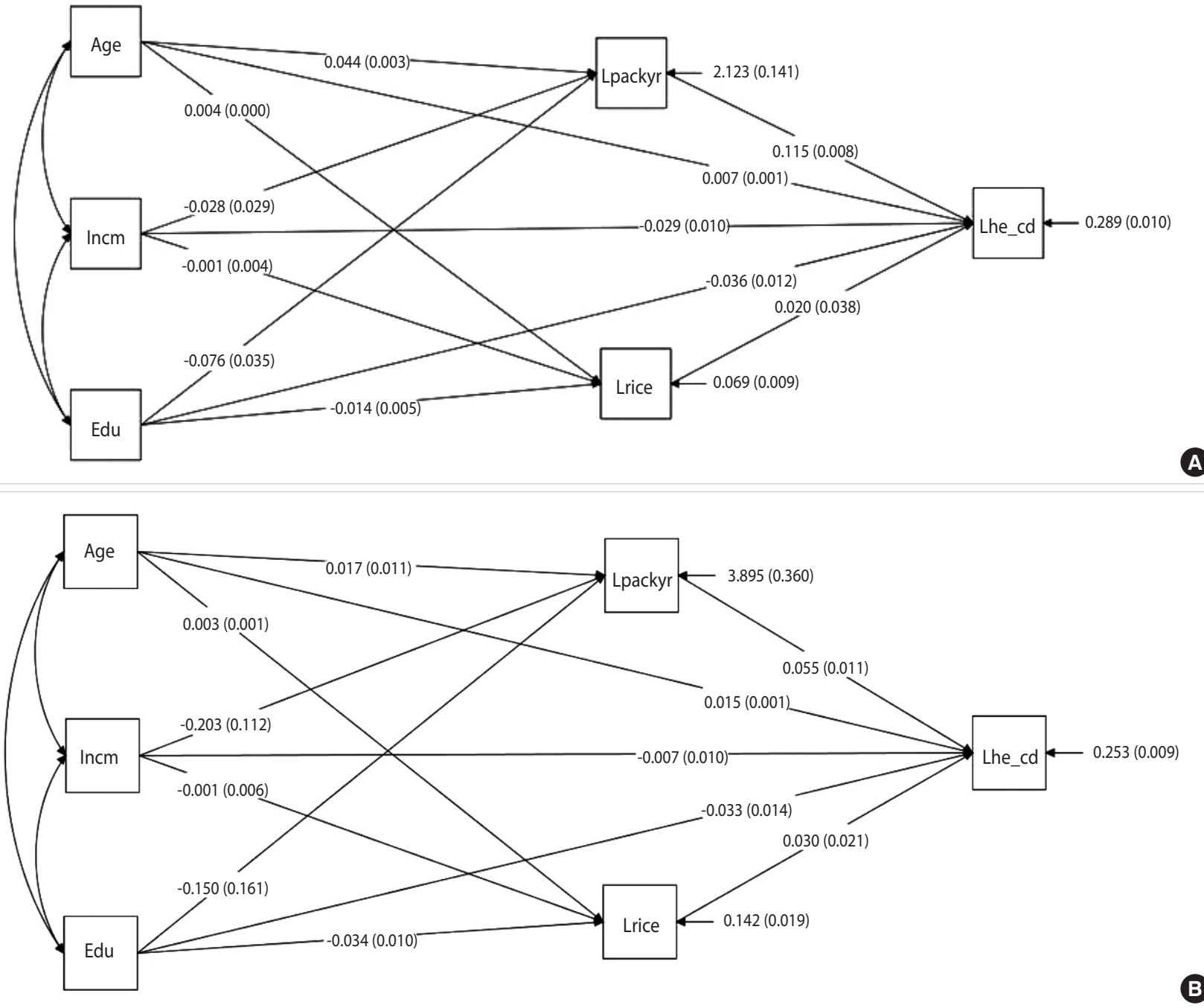

Figure 1. Path analysis of the overall associations of blood cadmium levels with smoking pack-years and social determinants including income level, education level, and occupation classification in (A) male and (B) female. Values are presented as $\beta$ ( $p$-value). Lpackyr, logtransformed pack year; Incm, income; Lhe_cd, log-transformed cadmium; Edu, education; Lrice, log-transformed rice.

Cd levels can be interpreted as the result of confounding by smoking status. However, the relatively small decrease in the magnitude of the association among female after controlling for smoking could be interpreted in light of previous studies reporting the high prevalence in Cd level among female [13]. However, it seems more likely that the results in our study are due to the low reliability of self-reported smoking among female, as a previous study reported unrealistically low rates of smoking prevalence in Asian female due to under-reporting [14]. Although we replaced the self-reported smoking variable among female with urinary cotinine levels, the results were similar after controlling for urinary cotinine levels, which can be interpreted as indicating that confounding effect of urinary cotinine levels was lower among female than among male.

Therefore, smoking made a significant contribution to the as- sociation between income and blood Cd levels in male, but not in female. In order to analyze the remaining association between income and blood Cd levels, education level and occupation classification were additionally controlled. Doing so eliminated the association between income and blood Cd levels. Integrating these findings, the association between income and blood Cd levels appears to result from confounding by smoking status and education level.

Previous studies have investigated associations between smoking status and Cd exposure. According to a recent meta-analysis reported by Hecht et al. [15], the correlation coefficient between cigarette smoking and Cd levels was 0.540. The associations found between cigarette smoking and Cd levels were 0.546 in this study (0.663 in male and 0.316 in female). Moreover, the present study demonstrated this association not only with cigarette smok- 
ing as a self-reported categorical variable, but also with pack-years and urinary cotinine levels, making our results more sophisticated than those of previous studies.

Female tended to have higher blood Cd levels in this study, and several former studies have reported that the health effects of toxic metals differ in prevalence or manifest differently in male and female [13]. Vahter et al. [13] reported that Cd-related health effects were more common among female than male, and hypothesized that this may have been due to differences in sensitivity to toxic effects; however, it remains unclear whether that is the case, as it is possible that their findings merely reflected Itai-itai disease, which involves a combination of kidney damage, osteomalacia, and osteoporosis, is the most advanced form of Cd-induced disease, and it has been reported to be caused by consumption of rice that is heavily contaminated by Cd emitted from mines $[16,17]$. A previous study also found that Itai-itai disease more strongly affected elderly, multiparous female; however, the degree to which those findings could be interpreted as showing a causal relationship relevant for risk assessment is limited [18].

Several studies have reported that Cd exerts estrogenic effects [14-19]. Based on those results, Cd was found to mimic estrogens in breast cancer cells as a result of its ability to form a high-affinity complex with the hormone-binding domain of the estrogen receptor [20].

One of the major strengths of this study is its use of the KNHANES, a representative data source. The KNHANES is a cross-sectional, nationally-representative survey of the general population in Korea, annually conducted by the KCDC as part of the Ministry of Health and Welfare. Although the design was cross-sectional, the risk of an inverse association was relatively low, because socioeconomic determinants are formed throughout a long-term period, and blood Cd accumulates for a long period in the human body. Although smoking is associated with both low socioeconomic status and blood Cd levels, the association between socioeconomic status and $\mathrm{Cd}$ levels remains unclear. In cross-sectional data from the KNHANES, blood Cd levels were significantly higher among those with a low income and less formal education. Smoking history contributed to these associations, but did not explain them entirely.

\section{CONFLICT OF INTEREST}

The authors have no conflicts of interest to declare for this study.

\section{ACKNOWLEDGEMENTS}

None.

\section{AUTHOR CONTRIBUTIONS}

Conceptualization: YJ, SIC. Data curation: YJ. Formal analysis: YJ. Funding acquisition: None. Methodology: YJ. Project administration: None. Visualization: YJ. Writing - original draft: YJ. Writ- ing - review \& editing: YJ, SIC.

\section{ORCID}

Yongho Jee: https://orcid.org/0000-0003-0365-8302; Sung-il Cho: https://orcid.org/0000-0003-4085-1494

\section{REFERENCES}

1. Järup L, Berglund M, Elinder CG, Nordberg G, Vahter M. Health effects of cadmium exposure - a review of the literature and a risk estimate. Scand J Work Environ Health 1998;24:1-51.

2. Nriagu JO, Pacyna JM. Quantitative assessment of worldwide contamination of air, water and soils by trace metals. Nature 1988; 333:134-139.

3. Pacyna JM, Pacyna EG. An assessment of global and regional emissions of trace metals to the atmosphere from anthropogenic sources worldwide. Environ Rev 2001;9:269-298.

4. Nordic Council of Ministers. Cadmium review; 2003 [cited 2019 Jul 2]. Available from: http://www.who.int/ifcs/documents/forums/ forum5/nmr_cadmium.pdf.

5. Lee HS, Cho YH, Park SO, Kye SH, Kim BH, Hahm TS, et al. Dietary exposure of the Korean population to arsenic, cadmium, lead and mercury. J Food Compost Anal 2006;19:S31-S37.

6. Lewis R. Metals. In: LaDou J, editor. Current occupational \& environmental medicine. 4th ed. New York: McGraw-Hill; 2007, p. 418-423.

7. Jee SH, Samet JM, Ohrr H, Kim JH, Kim IS. Smoking and cancer risk in Korean men and women. Cancer Causes Control 2004;15: 341-348.

8. Son JY, Lee J, Paek D, Lee JT. Blood levels of lead, cadmium, and mercury in the Korean population: results from the Second Korean National Human Exposure and Bio-monitoring Examination. Environ Res 2009;109:738-744.

9. Tyrrell J, Melzer D, Henley W, Galloway TS, Osborne NJ. Associations between socioeconomic status and environmental toxicant concentrations in adults in the USA: NHANES 2001-2010. Environ Int 2013;59:328-335.

10. McKelvey W, Gwynn RC, Jeffery N, Kass D, Thorpe LE, Garg RK, et al. A biomonitoring study of lead, cadmium, and mercury in the blood of New York city adults. Environ Health Perspect 2007; 115:1435-1441.

11. Marmot MG, Shipley MJ, Rose G. Inequalities in death--specific explanations of a general pattern? Lancet 1984;1:1003-1006.

12. Muthén LK, Muthén BO. Mplus user's guide; 2015 [cited 2019 Jul 2]. Available from: https://www.statmodel.com/download/usersguide/MplusUserGuideVer_7.pdf.

13. Vahter M, Akesson A, Lidén C, Ceccatelli S, Berglund M. Gender differences in the disposition and toxicity of metals. Environ Res 2007;104:85-95.

14. Jung-Choi $\mathrm{KH}$, Khang, $\mathrm{YH}$, Cho HJ. Hidden female smokers in Asia: a comparison of self-reported with cotinine-verified smoking prevalence rates in representative national data from an Asian 
population. Tob Control 2012;21:536-542.

15. Hecht EM, Landy DC, Ahn S, Hlaing WM, Hennekens CH. Hypothesis: cadmium explains, in part, why smoking increases the risk of cardiovascular disease. J Cardiovasc Pharmacol Ther 2013; 18:550-554.

16. Friberg L, Elinder C, Kjellstrom T, Nordberg GF. Cadmium and health: a toxicological and epidemiological appraisal Volume 1 : exposure, dose, and metabolism. Boca Raton: CRC Press; 1985, p. 257-290.

17. Ogawa T, Kobayashi E, Okubo Y, Suwazono Y, Kido T, Nogawa K. Relationship among prevalence of patients with Itai-itai disease, prevalence of abnormal urinary findings, and cadmium concentrations in rice of individual hamlets in the Jinzu River basin, Toy- ama prefecture of Japan. Int J Environ Health Res 2004;14:243252.

18. Nishijo M, Satarug S, Honda R, Tsuritani I, Aoshima K. The gender differences in health effects of environmental cadmium exposure and potential mechanisms. Mol Cell Biochem 2004;255:8792.

19. Choe SY, Kim SJ, Kim HG, Lee JH, Choi Y, Lee H, et al. Evaluation of estrogenicity of major heavy metals. Sci Total Environ 2003;312:15-21.

20. Garcia-Morales P, Saceda M, Kenney N, Kim N, Salomon DS, Gottardis MM, et al. Effect of cadmium on estrogen receptor levels and estrogen-induced responses in human breast cancer cells. J Biol Chem 1994;269:16896-16901. 